\title{
Special issue of synthese on new directions in the epistemology of modality: introduction
}

\section{Antonella Mallozzi ${ }^{1}$}

Published online: 12 August 2019

(c) Springer Nature B.V. 2019

The fourteen papers in this collection offer a variety of original contributions to the epistemology of modality. In seeking to explain how we might account for our knowledge of possibility and necessity, they raise some novel questions, develop some unfamiliar theoretical perspectives, and make some intriguing proposals. Collectively, they advance our understanding of the field.

In Part I of this Introduction, I give some general background about the contemporary literature in the area, by sketching a timeline of the main tendencies of the past twenty-five years or so, up to the present debates. Next, I focus on four features that largely characterize the latest literature, and the papers in the present collection in particular: (i) an endorsement of the importance of essentialism; (ii) a shift to a "metaphysics-first" approach to modal epistemology; (iii) a focus on metaphysical modality as opposed to other kinds of modality; and (iv) a preference for non-uniform modal epistemology.

In Part II, I present the individual papers in the volume. These are organized around the following four chapters, based on their topic:

(1) Skepticism and deflationism Metaphysical Challenges

1. Justin Clark-Doane-Metaphysical and Absolute Possibility

2. Graham Priest-Metaphysical Necessity: A Skeptical Perspective

Epistemological challenges

3. Jennifer Wang-The Epistemological Challenge to Modal Primitivism

4. Frank Jackson-Deflationism about the Necessary a Posteriori and TwinEarth

5. Anand Vaidya and Michael Wallner-The Epistemology of Modality and The Problem of Modal Epistemic Friction

Antonella Mallozzi

amalloz1@providence.edu

1 Providence College, 1 Cunningham Square, 139 Siena Hall, Providence, RI 02918, USA 
(2) Essentialism

6. Antonella Mallozzi-Putting Modal Metaphysics First

7. Boris Kment-Essence and Modal Knowledge

8. Mark Jago_-Knowing How Things Might Have Been

9. Bob Hale-Essence and Definition by Abstraction

10. Philip Goff_Essentialist Modal Rationalism

(3) Non-essentialist accounts

11. Francesco Berto-Taming the Runabout Imagination Ticket

12. Stephen Biggs and Jessica Wilson-Abduction vs. Conceiving in Modal Epistemology

13. Amie Thomasson-How Can We Know Metaphysical Modal Truths?

(4) Applications

14. Gabriel Rabin-Modal Rationalism and the Demonstrative Reply to the Scrutability Argument Against Physicalism

\section{Part I}

\subsection{The general issue}

We often have a strong sense that things might have been different; we might regret having done something and wish we had made a different choice, or perhaps feel relieved realizing that we might have just avoided a dangerous or uncomfortable situation. And that is not just at the individual level. It is natural to think, for example, that earth might not have been warming and ice might not have been melting in the last decades, had we humans not acted so recklessly with our fossil fuel emissions. Likewise in the case of things that are not quite up to us. We all probably agree that there might have been more zebras than there actually are; that there might not have been water on earth, so that life would have never developed; or, that a second moon might have been orbiting around us. For any (contingent!) actual fact we can think of, it strikes us that a myriad of alternative possibilities could have been actual instead. On the other hand, we also have an opposite sense that many things could not possibly have been different. It is widely believed, to mention a couple of familiar examples, that given that the chemical composition of water is $\mathrm{H}_{2} \mathrm{O}$, water could not have had another molecular constitution. Or that, regardless of whether humans ever used arithmetic, the arithmetical laws could not have been different.

In addition, modal thinking has widespread practical applications. Reasoning about what is and is not possible, and evaluating counterfactual scenarios, is crucial to our everyday life; for example, in making choices and planning future action, in learning from experience, as well as in interpreting and evaluating other people's behavior. Modal thinking is also a key theoretical tool in scientific practice, where assessing possible outcomes, probabilities, and counterfactuals helps researchers formulate hypotheses and predictions. Even at the socio-political level (as Achille Varzi once 
pointed out to me), our ability to work for a better world may be to an important extent a function of our ability to imagine and evaluate other possible worlds, that is, other ways our own world could be.

However simple and straightforward all this may sound, things get extremely complicated when we try to explain modal thinking, its outputs, and their epistemic status. The main question how do we know about possibility and necessity? branches out in several more specific directions. What are the distinctive epistemic means and methods involved in gaining modal knowledge? How do they reliably lead us to form true beliefs about modality? Which specific constraints must be in place for our beliefs about modality to be justified? Is such a justification a priori, or empirical? How can we answer modal skepticism, which challenges us to explain how we can access modal facts if we lack any perceptual or causal connection with them? How can we ward off modal error, that is, how can we tell when apparently possible scenarios are not genuinely possible? Does everyone use the same epistemic means and methods for forming modal beliefs, and across different contexts, or can they vary?

Focusing on the central issue of how we know about possibility and necessity, ${ }^{1}$ I will map out the main tendencies in the literature over the past twenty-five years or so, up to the present debates, by sketching a tripartite timeline. (Note that the timeline is not meant to be strictly chronological. As we will see, later thinkers may fit squarely into an earlier generation; likewise, earlier ones may have anticipated current trends). While somewhat simplified, this should be a useful tool for navigating the contemporary debate.

\subsection{The first generation-intuition, conceivability, imagination}

Historically, within Western thought, intuition, conceivability, and imagination broadly understood have been the chief candidates for explaining how we know about possibility and necessity. Think of classical Cartesianism, where the source of our modal knowledge is a distinctive kind of intellectual grasp. But think also of Hume's cognitive psychology, where all our modal beliefs derive from experientially-informed imagination. This tradition has been pursued in contemporary modal epistemology by a number of authors. Going back about twenty-five years to Yablo's 1993 seminal paper, what we might call the "first-generation" of studies in contemporary (post-Kripkean) modal epistemology aims to explain knowledge of modality by appealing to our broadly imaginative and intuitive capacities. It is important to notice that, methodologically, all those theories focus on individuating and giving an account of the distinctive cognitive/epistemic means and methods involved in modal knowledge. In doing so, they adopt a "means-first" approach to modal epistemology, as I call it. This approach has been prominent also throughout the second generation, until very recently. Going "means-first" in modal epistemology is in effect to tackle the central question of how we know about modality head-on. First-generation

\footnotetext{
${ }^{1}$ I will mostly speak of knowledge of modality here. However, unless otherwise specified, what I say is meant to be applicable to more modest epistemological targets, such as justified modal belief or understanding of modality, and to be neutral enough to accommodate internalist as well as externalist epistemological frameworks.
} 
thinkers put forward detailed accounts of conceivability, imagination, and intuition, and of their epistemic powers for gaining modal knowledge. (For an illuminating taxonomy of our hypothetical attitudes, see Balcerak Jackson 2016). Main examples of such first-generation studies include the above-mentioned Yablo 1993; Menzies 1998; BonJour 1998; Chalmers 2002; Bealer 2002; Gregory 2004; Kung 2010; Ichikawa and Jarvis 2011; Chudnoff 2013. (See also the papers in the now classic Gendler and Hawthorne 2002). Perhaps unsurprisingly, most of these modal epistemologists are also heavily inclined to some form of rationalism, although typically only "moderate". (Peacocke 1999 deserves a separate mention here. His account differs from those mentioned above in that it does not rest on any particular notion of conceivability, imagination, or intuition. For Peacocke, modal knowledge is instead a matter of (implicit) knowledge of certain principles of possibility. Still, his work fits squarely within the first-generation rationalist camp.)

\subsection{The second generation - the empiricist counterwave}

A second-generation of studies has brought about a forceful empiricist counterwave in modal epistemology. While still focusing on the distinctive means and methods involved with modal knowledge, thus maintaining a means-first approach, those authors introduce the idea that we gain modal knowledge empirically. Most secondgeneration thinkers share a wider research agenda that frames modal investigation as an extension of scientific investigation, and often move from naturalist and externalist stances in epistemology. It is not easy to map out all such proposals; but two main strands in particular should be mentioned.

The first one continues to tie modal knowledge to our imaginative capacities, though in a novel way, as deployed in counterfactual reasoning. In counterfactual supposition aimed at gaining modal knowledge, quasi-perceptual imagining and off-line simulation are often thought to play a crucial role (see e.g. Hill 2006; Williamson 2007; Kroedel 2012; Vetter 2016). These proposals emerge within a larger context of increasing interest in the study of all aspects of our imaginative capacities, and their cognitive roles in particular (for a recent overview, see the essays in Kind and Kung 2016. See also Balcerak Jackson 2018; Kind forthcoming). This literature fruitfully integrates results from recent psychological studies on mental imagery, simulation, and pretence (e.g. Currie and Ravenscroft 2002; Nichols and Stitch 2003; Kosslyn et al. 2006; Liao and Gendler 2011) and on counterfactual reasoning (e.g. Byrne 2005); as well as from the study of counterfactuals in linguistics (e.g. Kratzer 2012). Yet another line of research explores the logic of imagination, by modeling our imaginative acts through various original possible-world semantics (e.g. Berto 2017; Casas-Roma Huertas and Rodríguez 2019).

On the other hand, some second-generation thinkers have inaugurated a whole new approach to the issue of modal knowledge by introducing unconventional, empirical means and methods as legitimate candidates for explaining modal knowledge. Empirical means were neglected in the discussion because of the (implicit or explicit) assumption that modal knowledge, by its very nature or structurally, must proceed a priori. (See Casullo 2003, 2010 for discussion of some traditional inferential princi- 
ples linking the epistemic and the modal—particularly the a priori and the necessary). Such means and methods include inductive and abductive inference (Roca-Royes 2017; Nolan 2017; Leon 2017), the use of scientific theories and arguments (Fischer 2016; Bueno and Shalkowski 2014); empirical knowledge of dispositions and abilities (Vetter 2015, 2016); and even perception (Hanrahan 2009; Legg 2012; Strohminger 2015; Legg and Franklin 2017). (For further proposals within this second-generation empiricist wave, see the essays in Fischer and Leon 2017). In a different fashion, Williamson 2013 has challenged the traditional distinction between a priori and a posteriori knowledge by questioning its very significance. For Williamson, our cognitive processes are not strictly empirical nor purely a priori according to traditional standards (imagination is a main example), to the effect that the a priori/a posteriori categories do not "cut at the epistemological joints". Epistemic justification is instead best conceived as "armchair" and straddling our ordinary epistemological categories. (For a recent discussion of the issue of a priori knowledge and justification, also in connection to imagination and understanding, see Boghossian and Williamson forthcoming).

A separate mention should also be given to various forms of conventionalism about modality and modal knowledge that developed in parallel with the other two strands. Conventionalists generally deny that our modal language describes real facts "out there" in the world (or other possible worlds!) and offer alternative normative accounts of the meaning and function of our modal expressions. Such non-descriptivist solutions, they hold, simplify in turn the issue of modal knowledge (e.g. Sidelle 1989; Sveinsdóttir 2008, 2013; Thomasson 2013, this volume, and forthcoming).

\subsection{The third generation-current trends in modal epistemology}

Moving on to the latest debates, we get to the third generation of thinkers. There seem to be at least four main common lines of thought among those authors, which are well represented in the present collection. (i) An endorsement of the importance of essentialism; (ii) a tendency towards a "metaphysics-first" methodology; (iii) the focus on metaphysical modality as opposed to other kinds of modality; (iv) a preference toward non-uniformity.

Let us look at each of those in turn.

\subsubsection{Essentialism}

We are witnessing an explosion of interest in essentialism within metaphysics. This neo-Aristotelian trend goes all the way back to the work of Kit Fine in the 1990s; particularly, to his thesis that metaphysical necessities hold in virtue of the essence or nature of things (Fine 1994). Fine's "canonical reduction" of metaphysical necessity to essence (as Teitel 2019 has called it) is the basis upon which third-generation thinkers build out a variety of individual accounts. The appealing, common idea they pursue is that, given the canonical reduction, modal knowledge can then be explained in a straightforward way in terms of knowledge of essence. Of course, it is then a crucial task to clarify what essences are and how we get to know them. Lowe $(2008,2012)$, 
Hale (2013), as well as arguably Kripke (1980), all put forward pioneering essentialist accounts of modal knowledge. The core, common idea is that modal knowledge proceeds inferentially, on the basis of certain bridge-principles, from knowledge of essence to knowledge of metaphysical necessity. Although there is a clear continuity between those early accounts and more recent ones, third-generation thinkers advance several original proposals, while addressing familiar criticisms against traditional essentialism (e.g. Jago this volume; Hale this volume; Kment this volume; Mallozzi 2018, this volume; Tahko 2017, 2018; Vaidya and Wallner this volume). Importantly, several third-generation essentialists (or "neo-essentialists", as I shall call them) maintain a continuity with modal empiricists, as well, in that they understand knowledge of metaphysical modality largely as an empirical matter. By drawing from Kripke's treatment of a posteriori necessities $(1971,1980)$, essences are held to be things that we may discover empirically, often scientifically. Notably, while essentialist deduction is still widely regarded as the canonical epistemic route to modal knowledge, certain "recombination strategies", as we may call them, have also emerged. Those strategies take elements that were originally distinctive of a particular modal epistemology (e.g. conceivability, or counterfactual reasoning) and recombine them with the requirement that some knowledge of essence must be in place for gaining modal knowledge. The resulting theories, while positively essentialist, look hybrid according to traditional classifications (e.g. Goff this volume, who combines essentialism with conceivability; Kment this volume, who combines essentialism with conceivability, as well as counterfactual reasoning). ${ }^{2}$ Recombination strategies can be roughly located within the broader recent tendency to pursue "non-uniformity" in modal epistemology: see sect. (1.4.4.) below. (Specifically, recombination theories qualify as locally non-uniform, because they hold that multiple mental operations or methods jointly contribute to access truths within the same modal sub-field-in this case, the sub-field of metaphysical modality). ${ }^{3}$

Further key issues on the neo-essentialist agenda, as we will see, include the causal and non-causal roles of essential properties, and their distinctive tie with explanation; the structure and epistemic fertility of natural kinds; the ontology of essence-particularly the abstract cases and how we might access them a priori; the connection between essentialist laws and other metaphysical laws, as well as with the laws of nature.

\subsubsection{A metaphysics-first approach to modal knowledge}

Remarkably, many of the latest accounts turn away from the debates concerning the epistemic means and methods involved with modal knowledge, which occupied the previous two generations of thinkers. Instead, they take on the investigation of modal knowledge by first examining what this knowledge depends on or how it is constrained. This important methodological switch introduces what I have called a "metaphysicsfirst" approach to modal epistemology (inspired by Devitt 2010). The main idea is that

\footnotetext{
2 Recombination strategies can also be non-essentialist. A recent example is Dorhn (2019), who joins Yablo's conceivability with analogic reasoning.

${ }^{3}$ For a full taxonomy, see my "Non-Uniform Modal Epistemology", ms.
} 
we should start our inquiry by first trying to get some grasp on the nature of modality itself, as those metaphysical findings will be a helpful basis to answer the epistemological questions. And the more we know about the nature of modality, the better we can pursue and answer the epistemological questions. This is in a way a "return" to modal metaphysics, as I suggest below (this volume). The (first- and second-generation) epistemology of modality of the past two decades has been itself a response to the philosophy of modality up to that point, which had focused on the logic, semantics, and metaphysics of modality without much concern for the epistemology. Then, thanks to the above-mentioned Yablo's (1993) study of conceivability, van Inwagen's (1998) epistemological challenge, as well as the essays in Gendler and Hawthorne's (2002) anthology, the issue of modal knowledge came into full view. However, this theoretical correction in favor of epistemology in the long run lead to a neglect of discussing the connection to modality itself - of its nature and scope-which now requires a counterbalancing.

In his 1999 Peacocke stressed the importance of "providing, for any given area, a simultaneously acceptable metaphysics and epistemology” (1). He called this difficult theoretical task the "Integration Challenge". The metaphysics-first methodology gives us a promising guide to address the Integration Challenge, and to gain thereby a fuller picture of a given area of inquiry. Generally speaking, how we should learn about X depends on what $\mathrm{X}$ is; so, we need some grasp on what $\mathrm{X}$ is before addressing the issue of how we know about $X$. This methodology encourages us to find out as much as possible about the nature of the target entities of our epistemic questions, for the nature of those entities constrains the relevant answers. Thus, in the case of modality, we should have some grasp on what modality is or the nature of modal truth, in order to address the issue of how we know about modality.

More or less explicitly, most authors in the present collection endorse this novel approach in modal epistemology. Throughout the volume, we see a consistent effort to get clearer about the modal metaphysics as a tool to access the epistemology; which is exemplified by the discussion of core topics such as the nature, scope, and function of the modal notions; the metaphysics of essence and essential properties; as well as the regulative role that relations of grounding, principles of mereology, and the metaphysical laws more generally might play for what is possible and necessary.

Peacocke (2019) also explicitly defends a metaphysics-first approach to issues in semantics and epistemology. As he cashes it out, this is the thesis that (for a large number of domains) the metaphysics of a domain is explanatorily prior or more fundamental than the ways we think about that domain (cf. similarly Devitt 1996: §4.12; 2010). Importantly, Peacocke points out how this explanatory priority of the metaphysical domain might not always involve a corresponding priority in the context of discovery. For we might find out about the epistemology (or semantics) of a domain first, and only later learn about its metaphysics. Still, this in no way affects the explanatory priority of the metaphysical domain. While I agree with Peacocke's point, I should clarify that, as understood here, the metaphysics-first approach to modal epistemology also concerns to an important extent a priority in the context of discovery. However, this is a regulative not a descriptive aspect of the approach. Namely: granted that we do sometimes find out about the epistemology of X prior to its metaphysics, we should choose, as a general guideline and where possible, to start our investigation of the 
epistemology of $\mathrm{X}$ by first tackling the metaphysics of $\mathrm{X}$. And the reason why we should do so, as mentioned, is that our metaphysical findings about $\mathrm{X}$ will help us account for how we know about $\mathrm{X}$. The regulative thesis is thus itself supported by the explanatory priority of the metaphysical domain.

\subsubsection{Targeting metaphysical modality}

Most recent accounts of modal knowledge specifically target metaphysical modality, as opposed to other kinds of modality (e.g. logical modality, nomological modality, etc.) This marks a departure from the previous generation, since most modal empiricists tended to push knowledge of metaphysical modality into the background, while focusing on knowledge of ordinary practical, nomic, and dispositional modalities (e.g. Roca-Royes 2017; Strohminger 2015; Vetter 2016). A main concern of modal empiricism was that focusing on metaphysical modality would make us overlook our knowledge of ordinary modal claims, as well as misguide us into believing that modal knowledge must proceed a priori. Echoing van Inwagen's (1998) distinction between everyday vs. remote modal knowledge, modal empiricists proposed that our epistemological inquiry focus on the former, apparently more accessible cases, and engage with knowledge of "remote" metaphysical scenarios derivatively, often in connection to the broader study of philosophical methodology. 4

It is certainly a non-trivial task to define what exactly metaphysical modality picks out, especially compared to the other modalities, on which we seem to have a better grip. Still, this should not throw us into skepticism. In fact, there is a lot that we can say to clarify this notion, as well as promising directions to advance our understanding going forward (though see Priest this volume for an opposite view). First of all, we should distinguish metaphysical modality from various types of non-alethic deontic and epistemic modalities (i.e., those modalities concerned with the 'can' and 'ought' of moral, practical, and epistemic permission and obligation). On the other hand, we should also distinguish it from other alethic modalities like logical modality (which roughly is governed by the axioms of logic and basic truth-preserving patterns of inference), or physical-nomological modality (which roughly is governed by the actual laws of nature). Moving on to a more positive characterization of metaphysical modality, there is seemingly a distinctive way in which this has to do with the nature of things, and with how reality in its most general traits could and must have been. Philosophers working within different traditions such as those of Kripke, Lewis, Fine, as well as Williamson, will likely find the broad talk of the nature of things and the most general traits of reality equally congenial (in fact it is common to introduce metaphysical possibility and necessity simply in terms of ways things might have been, and must have been respectively). Of course, we can then further specify this neutral characterization by adding various theoretical commitments. As noted, there is a widespread tendency in the current literature to elucidate metaphysical modality by delving into such notions as essence, metaphysical laws, and grounding and mereological relations. And while no commitment to any such notion is strictly required

\footnotetext{
4 van Inwagen is skeptical that remote modal knowledge is within our reach. On the other hand, he does not explicitly locate metaphysical modality within that area.
} 
for meaningful metaphysical modal talk, their investigation does seem to give us a deeper understanding of what metaphysical modality is about.

On the other hand, it is also somewhat usual in the literature to characterize metaphysical modality in terms of absolute, or the strongest, or the widest modality, probably following allusive remarks in Kripke (1980), as well as Lewis (1986). This is not uncommon even among essentialists: Hale for example describes metaphysical necessity as "absolute" in the sense of "what holds true absolutely unconditionally, or "come what may"' (2013: 99. See also Fine 2002; Kment 2014; Lowe 2012). Although perhaps fascinating, those glosses do not seem especially insightful to help us understand the distinctive subject matter of metaphysical modality. In fact, they are potentially misleading, since arguably they capture quite squarely logical modality. Briefly, note that logical necessities plausibly include the fundamental laws of logic and truth-preserving patterns of inference, as well as their instances. Their modal force is commonly partly attributed to their having a certain form, namely generality, which grants them in turn a special inferential status. (As McFetridge put it, logical necessity is absolute, and the strongest, in the sense that we are prepared to deploy a logically necessary proposition as a premise in reasoning over the unrestricted range, from any supposition whatsoever. McFetridge 1990: 153-154. See also Divers and Elstein 2012; Divers and González-Varela 2013). Logical necessities seem in effect ideal candidates for the "strongest" or "widest" necessities or necessities "come what may" (even for Quine, logical necessities are the last ones we would give up). Logical possibilities, in turn, are only minimally constrained in terms of coherence. Simplifying a bit, just about anything is logically possible as long as it does not violate (at least) the principle of noncontradiction. ${ }^{5}$ Thus, logical possibility seems an ideal candidate for "absolute" or the "widest" possibility. By contrast, metaphysical modality strikes us as quite restricted and qualified - at the very least, as more restricted and qualified than logical modality. Think of traditional examples. Scenarios where, say, Saul Kripke is Rudolph Carnap's son, or where iron has atomic number 25 (it is actually 26!) are not genuine metaphysical possibilities (or at least so most metaphysicians believe). Still, they are coherent, in the sense that there is no contradiction in merely supposing that they hold, while setting aside metaphysical axioms in conjunction with certain truths about the actual world. Vice-versa, the fact that Saul Kripke must have had the parents he actually has, or that iron's atomic number must have been 26 , while certainly necessary, are far from being "absolute", "unconditional", and the like. Fairly precise conditions have to be in place instead. The relevant-possible and actual-worlds must have a certain nomological and metaphysical profile and, arguably, certain essentialist laws must hold. These quick considerations are not meant to show that logical modality is absolute (or any of the other properties I mentioned). Still, they should suffice to see that it might be hard to draw a line between metaphysical modality and logical modality given the above characterization. (Similarly Clarke-Doane this volume; van Inwagen 1998: 82, fn.9). Analogous remarks apply to Williamson's recent definition of metaphysical modality in terms of the broadest objective modality (2016; see also Strohminger and Yli-Vakkuri 2017). Moreover, it is worth noting

\footnotetext{
${ }^{5}$ Logical pluralists might want to be even more concessive and expand the range of possibilities to those that do not violate the logical rules that are set by the logic in question. (Thanks to Anand Vaidya for pointing this out).
} 
that Williamson operates with a technical notion of objectivity (as opposed to a more ordinary understanding of being "mind-independent" or otherwise "non-subjective"), which he draws from linguistics. "Objective" for him captures the property we might call of referential transparency, namely, the property of a sentence of "not [being] sensitive to the guises under which the objects, properties, relations and states of affairs at issue are presented" (2016: 454). Although objectivity qua referential transparency might help us draw a clearer line between logical modality and metaphysical modality, it also seems in need of further motivation. Additionally, Williamsons' approach has the disadvantage that it does not tell us about the content or subject matter of metaphysical modality — what those truths are about — but it only highlights a formal property of modal sentences. All in all, understanding metaphysical modality in terms of the nature of things and how reality in its most general traits could and must have been seems to better capture the distinctive, rich content of metaphysical possibility and necessity, and to indicate fruitful paths for further investigation. That is why I adopt it and recommend it over those other characterizations.

\subsubsection{Non-uniform modal epistemology}

A further thesis has been gaining attention in the latest debates, which I call "epistemic non-uniformity". This is a thesis concerning the architecture of modal epistemology. Claiming that modal epistemology is non-uniform means that knowledge of possibility and necessity need not proceed via one single epistemic route. Instead, multiple means and methods may be required for modal knowledge. Depending on the cases, we might need, for example, essentialist deduction, or conceivability, or counterfactual reasoning, in order to access possibility and necessity. Explaining such variations in means and methods for accessing modal truth, or in sources of justification, is not easy of course. Those seem to rest themselves on multiple factors, both subjectdependent (e.g., different people might use different routes to acquire the same bit of modal knowledge), and subject-independent (e.g. we might need different epistemic routes depending on the type of modal truths we are looking at: logical, metaphysical, dispositional, etc. But also depending on the circumstances at stake: perhaps the same subject might come to know the same modal truth through different routes, depending on the specific epistemic context she is in). As of now (July 2019), epistemic nonuniformity has not yet been directly discussed or worked out as a theory in print. But many think that this is the direction we should pursue (see Roca-Royes forthcoming; Mallozzi ms. cit. for developments). Importantly, pursuing non-uniformity represents a point of departure from the traditional literature, both historical and first-generation, which mostly aimed to give a single unified account of our knowledge of possibility and necessity (at least within the domain of metaphysical modality). Also notably, we can find gestures at non-uniformity already among second-generation thinkers (e.g. Fischer 2017; Leon 2017; Roca-Royes 2017, 2018; Strohminger 2015; Tahko 2017; Vaidya 2017). A further element of continuity with the previous generation is (in most cases) an empiricist approach to modal issues. But, in line with epistemic nonuniformity, the general atmosphere is one where modal epistemologists seem open to a whole variety of epistemic routes contributing to our access to modal truths, both empirical and a priori. 


\section{Part II}

Here is an outline of the four chapters of this special issue.

In Chapter (1), we find a few papers that discuss skeptical challenges and kinds of deflationism about modal knowledge. Some of them target directly our knowledge of modality as a whole (Wang; Vaidya and Wallner), or specific cases of it (Jackson). Others target certain modal notions themselves, with potential consequences for the epistemology (Clarke-Doane; Priest). Accordingly, I labeled the latter "metaphysical challenges" and the former "epistemological challenges". Vaidya and Wallner further suggest that we can push back serious epistemological challenges by appealing to essence. So, next we move on to some positive proposals, starting with essentialism.

Chapter (2) collects several accounts of modal knowledge as based on knowledge of essence. Hale, Jago, Kment, and Mallozzi all build their epistemological theories on the metaphysical assumption that metaphysical necessity depends on essence (the Finean "canonical reduction" mentioned above). Kment and Mallozzi take a largely empirical route; while Hale looks at specific cases of a priori knowledge of essence. Goff brings together essentialist knowledge and conceivability in a rationalist fashion.

Chapter (3) includes several non-essentialist theories of modal knowledge. Biggs and Wilson appeal to a novel notion of a priori abduction, especially against conceivability-accounts; Thomasson lays out a normativist account that ties modality and modal knowledge to our use of language and the rules that govern it. Berto explores the epistemic powers of imagination more generally, with potential gains for modal knowledge in particular.

Finally, in chapter (4), Rabin criticizes a familiar rationalist method of using a priori entailment as a tool to reject physicalism.

Let us now turn to briefly present the individual papers in this special issue.

\subsection{Chapter 1: skepticism and deflationism}

\subsubsection{Metaphysical challenges}

In his essay, Metaphysical and Absolute Possibility, Justin Clarke-Doane examines the thesis that metaphysical possibility is "absolute". Whereas this thesis seems "widely alleged" in the literature, for Clarke-Doane it is "a mere article of faith". More precisely, Clarke-Doane criticizes the idea that metaphysical modality, as distinct from both epistemic (doxastic) and deontic modality, is modality in the "broadest objective" and "unrestricted" sense. Along similar lines to those I presented in (1.4.3.) above, ClarkeDoane points out that logical possibility, while distinct from epistemic and deontic notions, is still "dramatically more inclusive" than metaphysical possibility (especially when the logic in question includes contingent identity). For, many scenarios that seem to us metaphysically impossible are perfectly logically possible. Thereby, the notion of metaphysical modality is not suited to capture how the world could have been different in the most inclusive sense. Importantly, however, that metaphysical possibility is a restricted notion of possibility does not mean for him that it is uninteresting, or that it fails to "carve at the joints". Clarke-Doane concludes that metaphysical necessity 
is to absolute necessity what restricted notions of set are to the full iterative notion. Consequently, modal metaphysics should not be centered on it.

In Metaphysical Necessity: A Skeptical Perspective, Graham Priest questions the established view that there is a distinctive notion of metaphysical necessity - namely, one that is distinct from other notions of necessity, and in particular from analytic necessity and physical necessity. Priest mainly criticizes Kripke's (1980) views, by pointing out that they rest on two sorts of considerations. First, what Priest calls 'intuition pumps', namely thought experiments that do not strictly provide arguments. And, second, an argument for the (metaphysical) necessity of identities, which peculiarly appeals to the substitutivity of identicals (SI). Priest proceeds, first, to "pump intuitions" the other way, aiming to elicit a sort of "skeptical epoche" in the reader. Second, he challenges Kripke's argument. Against this, Priest argues that (SI) fails in a number of contexts, e.g. intentional and modal contexts. Moreover, (SI) fails in modal contexts when we assume a system of contingent identity. Why should one be entitled to assume the logic of necessary identity rather than contingent identity? Relying on (SI) is thus for Priest to beg the question in favor of metaphysical necessity, rather than to provide an argument.

\subsubsection{Epistemological challenges}

In her short piece, The Epistemological Challenge to Modal Primitivism, Jennifer Wang aims to show that the epistemological objection that we cannot know modal truths perceptually or via causal connection is wide-ranging. As Wang argues, this objection applies to all forms of realism about modality across the board. Namely, it applies both to reductionist accounts, which roughly hold that modal facts or properties can be reduced to other, non-modal entities (e.g. Lewis' realism, various sorts of combinatorialism, etc.); and to primitivist accounts, which hold instead that modal entities are primitive or not further reducible (e.g. modalism, essentialism, etc.). As a consequence, Wang concludes, the debate between reductionism and primitivism does not bear on modal epistemology. If the epistemological challenge "can be met by the reductionist via some extant epistemology of modality, it can be met by the primitivist in the same way".

Frank Jackson's essay, Deflationism about the Necessary A Posteriori and Twin Earth, defines deflationism about an example of a necessary a posteriori truth as the view that discovering that it is a necessary truth-that it is true throughout modal space-is not a discovery about the membership of modal space; it is nothing more than a discovery about the actual world. He calls such discoveries "Cambridge" discoveries about modal space. 'Actually there are electrons' is an example: all it took to learn that this sentence is necessarily true was something about the actual world. Jackson holds that if names can be treated as simple rigidified descriptions, the same is true for examples of the necessary a posteriori like 'Necessarily, anything that is Hesperus is Phosphorus'. He argues, however, using Twin-Earth style considerations, that many names cannot be handled in this way. Crucially, the sort of Twin-Earth considerations Jackson appeals to are not the traditional externalist ones. He claims that "the important message of Twin Earth has been widely misunderstood". Instead, Jackson sketches an alternative deflationist strategy for handling cases of the necessary a 
posteriori containing names that cannot be treated as simple rigidified descriptions. According to him, such cases involve de se names, which crucially partly rely on the role of producers in determining what/whom the name refers to.

In The Epistemology of Modality and The Problem of Modal Epistemic Friction, Anand Vaidya and Michael Wallner point out that the three main theories of modal knowledge of the past 20 years- namely, conceivability-theory, counterfactual-theory, and deduction-theory - suffer from a common problem. In order for our conceivability, imaginative, and deductive exercises to lead to modal knowledge, they need to be adequately constrained - i.e., something must produce a sort of "epistemic friction" on those exercises, so that they do not lead us astray. Furthermore, Vaidya and Wallner argue that the relevant constraints are essentialist propositions or principles. For each theory, they illustrate in detail how our exercises aimed at gaining modal knowledge are only successful when they do not violate the nature of things at stake. Thus, in different ways, all major accounts of modal knowledge rest on facts about essence. If that is correct, the question of how we know about essences turns out to be crucial for modal epistemology, as we must integrate an epistemology of essence in order to fully explain modal knowledge. While addressing that question is beyond the scope of Vaidya and Wallner's paper, that constitutes a nice bridging-point with the papers in the following chapter, which develop several essentialist routes to modal knowledge.

\subsection{Chapter 2: essentialism}

In Putting Modal Metaphysics First, Antonella Mallozzi aims to clarify knowledge of metaphysical modality starting from the metaphysics of essence. According to Mallozzi, essences have distinctive explanatory powers for how things are-in fact, they are superexplanatory. Mallozzi focuses on examples involving kinds and illustrates how essences are best understood in terms of underlying cores which typically cause and explain many properties and behaviors that consistently co-occur in the instances of such kinds. This helps clarify in what sense essences are held to constitute the "nature" of things. Accordingly, against longstanding criticisms of being mysterious entities and the relic of a pre-scientific era, essences are instead things that we discover empirically, typically via scientific investigation. According to Mallozzi, we may thus have a key to the epistemology of central cases of metaphysical necessity. By building into the account a Kripkean bridge-principle connecting essence and necessity (' $I f$ $X$ is essentially $F$, then necessarily $X$ is $F^{\prime}$ ), Mallozzi holds that modal knowledge proceeds inferentially, from premises concerning the actual makeup of the world to conclusions about the non-actual and necessary. We infer what is necessarily true of things from our knowledge of what is essential to things, in the sense of playing such core causal-explanatory roles.

In Essence and Modal Knowledge, Boris Kment develops an account of modal knowledge that builds off his own modal metaphysics (2014). It is a central tenet of Kment's framework that modal properties are defined in terms of metaphysical laws, where the notion of a metaphysical law is a generalization of the concept of an essential truth. Thereby, much of our modal knowledge for Kment crucially depends 
on knowledge of the metaphysical laws, including essential truths. He discusses two ways in which we might acquire knowledge of such laws. (1) Abductively, via inference to the best explanation; for essential truths, and metaphysical laws more generally, play a crucial role in causal and grounding explanations. And (2), by relying on our conceptual or linguistic competence; for competence with a term often requires (at least implicit) knowledge of part or all of the real definition of the thing picked out by the term, and for Kment real definitions are a type of essential truth. For example, to be competent with modal notions, you need to know (at least implicitly) that modality is essentially connected to the metaphysical laws. This knowledge, when combined with other information about the metaphysical laws gained by routes (1) and (2), allows you to acquire modal knowledge "in a variety of different ways." For instance, you can establish the metaphysical possibility of $\mathrm{P}$ by conceiving of a scenario in which $\mathrm{P}$ holds - a process that often makes crucial use of counterfactual reasoning.

Mark Jago's Knowing How Things Might Have Been also offers an account of modal knowledge that moves from the canonical reduction of metaphysical necessity to essence. Jago rejects both conceivability-based and counterfactual-based accounts and holds instead that we can explain our knowledge of metaphysical modality by way of our (implicit or explicit) knowledge of essence. Like others, Jago aims to refute longstanding skepticism against essences; to do so, he lays out a metaphysical account according to which essences are simply bundles of located properties. Moreover, for Jago we can refer and single out these bundles straightforwardly, in thought or language, by conceptualizing them under kinds. Knowledge of essence is thus secured by a reliable connection with reality, which is due in part to the way we think about objects and forms beliefs about them. Knowledge of essence, in turn, leads us to knowledge of necessity and possibility via a conceptual connection between essence and necessity. For Jago, "it is a conceptual truth that whatever is essentially $F$ is necessarily $F$ "; thereby, possessing the concepts of 'essence' and 'necessity', together with the relevant essentialist knowledge jointly results in knowledge of necessity.

Essence and Definition by Abstraction by Bob Hale, to whose memory this volume is dedicated, discusses an apparent tension between definition by abstraction and real definition, for the case of numbers. Hume's Principle defines the number operator by means of definition by abstraction, which means (at least according to neo-Fregeans) that the definition is partly stipulative and implicit. This seems to clash with the familiar Aristotelian conception of real definition as capturing the essence of the thing. Hale offers a way out, which reconciles neo-Fregean implicit definitions with essentialism. In certain cases, like the one of numbers at stake, definition by abstraction gives us a priori access to the essence of the entity that is being defined. As he puts it, "on the basis of these definitions one can gain knowledge a priori of the nature of cardinal and natural numbers." Hale further clarifies that there is no "happy coincidence" between the definition of the word and the essence of the thing; let alone that numbers somehow depend on us for their existence. "Definition by abstraction creates no objects. What, if successful, it creates is only a concept". Otherwise put, while we fix the meaning of a word by defining it so-and-so, that there exists a property of being so-and-so is entirely independent of any such definition.

In his short piece, Essentialist Modal Rationalism, Philip Goff aims to refine the picture of modal knowledge he sketched in his recent book (2017), to avoid cer- 
tain counterexamples and secure a general account. Goff puts forward a kind of conceivability-based rationalism that is consistent with the Kripke-Putnam cases by integrating essentialist knowledge. More specifically, for Goff rational coherence entails possibility when one grasps the essential nature of what she is conceiving of. However, it seems that there might be propositions that are possible even though we cannot grasp the nature of the entities they involve. This may be because those very entities are 'brute one offs', namely they lack a defining nature. To address these sorts of counterexamples, Goff clarifies that coherent conceiving and possibility go together when one grasps the full reality of what is being conceived, which may involve in particular grasping information concerning the entities' identity.

\subsection{Chapter 3: non-essentialist accounts}

\subsubsection{Imagination}

Francesco Berto's Taming the runabout imagination ticket defends our imaginative exercises against the charge of being merely arbitrary and therefore lacking epistemic power. Specifically, Berto singles out a kind of reality-oriented mental simulation and provides a formal semantics to model its central features. Imagination thus understood is similar to a kind of subjunctive thinking, and leads us to gain newly formed conditional beliefs, similar to a kind of "simulated belief revision". Although Berto does not address the issue of modal knowledge directly, his account shows how imagination is tied to modal thinking, as well as how it can have epistemic value for knowledge of counterfactuals. Thus, if successful, Berto's proposal both answers an epistemic challenge and sets the ground for developing a novel account of modal knowledge based on imagination.

\subsubsection{Abduction}

In Abduction vs. Conceiving in Modal Epistemology, Stephen Biggs and Jessica Wilson compare abduction-based vs. conceiving-based modal epistemologies and argue in favor of the former. Crucially, Biggs and Wilson put forward a new conception of abduction (or inference to the best explanation) as a priori, rejecting what they see as the "widespread but mistaken assumption that abduction is an a posteriori mode of inference". They first argue that the view that abduction is a priori has historical precursors, in Kant's notion of the synthetic a priori and Carnap's notion of explication. They then argue that the common assumption that abduction is a posteriori is mistaken in failing to appreciate that abductive principles are prescriptions for choosing between, not descriptions of, theories, and relatedly, that the ceteris paribus clauses associated with abductive principles shield them from empirical disconfirmation. Biggs and Wilson go on to argue that there are three main advantages of an abduction-based account of modal knowledge, so understood, over a conceiving-based account. First, an abduction-based account does better by way of overcoming modal indeterminacy and skepticism, thanks to its ampliative resources. Second, an abduction-based account does better by way of legislating between competing or incompatible dispositions 
to apply concepts, since abduction allows different theories of such dispositions to be compared and ranked, based on considerations of, among other things, relative explanatory power. And third, an abduction-based account better accommodates substantive philosophical disagreement about modal claims in such a way as to advance the dialectic, by measuring the explanatory costs of the parties' respective beliefs.

\subsubsection{Normativism}

In How Can We Come to Know Metaphysical Modal Truths? Amie Thomasson develops a normativist account of modality and modal knowledge, based on our use of language and the semantic rules that govern it. Thomasson argues that recent empiricist theories of modal knowledge are unable to solve the problem of how we can know specifically metaphysical modal truths. Treatments of modal discourse typically rely on the descriptivist assumption that our metaphysical modal claims track or describe certain features of our world, or other (possible) worlds. As a consequence, modal claims require (this or other-) worldly truthmakers, which causes several notorious epistemological problems. Thomasson rejects the descriptivist assumption and argues that doing so makes these classic epistemological problems show up very differently. The remaining versions of the epistemological problems, she argues, the modal normativist is well-positioned to solve. For her, modal knowledge is a matter of being able to explicitly convey the semantic rules that we implicitly master as competent speakers of our language. Accordingly, knowledge of metaphysical modality for Thomasson involves three elements specifically. First, mastering semantic rules and making them explicit. Second, a certain amount of empirical knowledge. And third, reasoning abilities. For Thomasson, normativism so understood further offers an evolutionary explanation of why we modalize as we do, since natural selection might have plausibly favored those capable of such activities.

\subsection{Chapter 4. Applications: conceivability and the mind-body problem}

In Modal Rationalism and the Demonstrative Reply to the Scrutability Argument Against Physicalism, Gabriel Rabin criticizes a familiar rationalist method of using a priori entailment as a tool to reject physicalism. Such arguments use modal rationalism, according to which "there are important, potentially constitutive, connections between a priori justification and metaphysical modality" to support the inference from an epistemic to a metaphysical gap between the physical and the mental. Rabin argues that this use of modal rationalism depends on a particular ambitious implementation of the rationalist program, which should be rejected on independent grounds. Rabin's argument belongs to the broad camp of the so-called phenomenal concept strategies, which locate the explanatory gap between the physical and consciousness in certain features of our representations for conscious experience, rather than in a metaphysical gap resulting from dualism. Specifically, Rabin's argument rests on a meta-semantic framework of reference-determination where terms get their meaning in large part by demonstrative use. According to Rabin, there is a fundamental "vital connection" between our phenomenal concepts and terms and demonstratives. Because of that, the 
physical truths alone, without the demonstrative truths, cannot entail a priori truths about consciousness. As a result, the a priori entailment from a demonstrative-less base fails. However, Rabin believes that integrating demonstrative truths into the entailment base offers a way to reconcile physicalism with a moderate kind of rationalism.

Acknowledgements Thanks to Nathan Bice, Paul Boghossian, Michael Devitt, David Papineau, Jonathan Schaffer, Anand Vaidya, and Michael Wallner for helpful conversation and feedback. Thanks also to Otávio Bueno and Wiebe van Der Hoek for their kind editorial guidance.

\section{References}

Balcerak Jackson, M. (2016). On the epistemic value of imagining, supposing, and conceiving. In A. Kind \& P. Kung (Eds.), Knowledge through imagination (pp. 41-60). Oxford: Oxford University Press.

Balcerak Jackson, M. (2018). Justification by imagination. In F. Macpherson \& F. Dorsch (Eds.), Perceptual imagination and perceptual memory (pp. 209-226). Oxford: Oxford University Press.

Bealer, G. (2002). Modal epistemology and the rationalist renaissance. In T. S. Gendler \& J. Hawthorne (Eds.), Conceivability and possibility (pp. 71-125). Oxford: Clarendon Press.

Berto, F. (2017). Impossible worlds and the logic of imagination. Erkenntnis, 82(6), 1277-1297.

Boghossian, P., \& Williamson, T. (Forthcoming). Debating the a priori. Oxford University Press.

BonJour, L. (1998). In defense of pure reason. Cambridge: Cambridge University Press.

Bueno, O., \& Shalkowski, S. (2014). Modalism and theoretical virtues: Toward an epistemology of modality. Philosophical Studies, 172(3), 671-689.

Byrne, R. (2005). The rational imagination. How people create alternatives to reality. Cambridge: MIT Press.

Casas-Roma, J., Huertas, A., \& Rodríguez, M. (2019). The logic of imagination acts: A formal system for the dynamics of imaginary worlds. Erkenntnis, 1-29.

Casullo, A. (2003). A priori justification. Oxford: Oxford University Press.

Casullo, A. (2010). Knowledge and modality. Synthese, 172(3), 341-359.

Chalmers, D. (2002). Does conceivability entail possibility? In T. S. Gendler \& J. Hawthorne (Eds.), Conceivability and possibility (pp. 145-200). Oxford: Clarendon Press.

Chudnoff, E. (2013). Intuition. Oxford: Oxford University Press.

Currie, G., \& Ravenscroft, I. (2002). Recreative minds: Imagination in philosophy and psychology. Oxford: Oxford University Press.

Devitt, M. (1996). Coming to our senses. A naturalistic program for semantic localism. Cambridge: Cambridge University Press.

Devitt, M. (2010). Putting metaphysics first. Oxford: Oxford University Press.

Divers, J., \& Elstein, D. (2012). Manifesting belief in absolute necessity. Philosophical Studies, 158(1), $109-130$.

Divers, J., \& González-Varela, J. E. (2013). Belief in absolute necessity. Philosophy and Phenomenological Research, 87(2), 358-391.

Dorhn, D. (2019). Modal epistemology made concrete. Philosophical Studies, 176(9), 2455-2475.

Fine, K. (1994). Essence and modality. Philosophical Perspectives, 8, 1-16.

Fine, K. (2002). The varieties of necessity. In T. S. Gendler \& J. Hawthorne (Eds.), Conceivability and possibility (pp. 253-282). Oxford: Clarendon Press.

Fischer, B. (2016). A theory-based epistemology of modality. Canadian Journal of Philosophy, 46(2), 228-247.

Fischer, B. (2017). Modal empiricism: Objection, reply, proposal. In B. Fischer \& F. Leon (Eds.), Modal epistemology after rationalism (pp. 263-280). Berlin: Springer.

Fischer, B., \& Leon, F. (2017). Modal epistemology after rationalism. Berlin: Springer.

Gendler, T. S., \& Hawthorne, J. (2002). Conceivability and possibility. Oxford: Oxford University Press.

Goff, P. (2017). Consciousness and fundamental reality. New York: Oxford University Press.

Gregory, D. (2004). Imagining possibilities. Philosophy and Phenomenological Research, 69(2), 327-348.

Hale, B. (2013). Necessary beings. An essay on ontology, modality, and the relations between them. Oxford: Oxford University Press. 
Hanrahan, R. (2009). Consciousness and modal empiricism. Philosophia, 37(2), 281-306.

Hill, C. (2006). Modality, modal epistemology, and the metaphysics of consciousness. In S. Nichols (Ed.), The architecture of imagination: New essays on pretense, possibility and fiction (pp. 205-236). Oxford: Oxford University Press.

Ichikawa, J., \& Jarvis, B. (2011). Rational imagination and modal knowledge. Noûs, 46(1), 127-158.

Kind, A. (Forthcoming). Imaginative experience. In U. Kriegel (Ed.), Oxford handbook of philosophy of consciousness. Oxford University Press.

Kind, A., \& Kung, P. (2016). Knowledge through imagination. Oxford: Oxford University Press.

Kment, B. (2014). Modality and explanatory reasoning. Oxford: Oxford University Press.

Kosslyn, S., Ganis, G., \& Thompson, W. (2006). Mental imagery: Against the nihilistic hypothesis. Trends in Cognitive Sciences, 7(3), 109-111.

Kratzer, A. (2012). Modals and conditionals. New and revised perspectives. Oxford: Oxford University Press.

Kripke, S. (1971). Identity and necessity. In M. K. Munitz (Ed.), Identity and individuation (pp. 135-164). New York: NYU Press.

Kripke, S. (1980). Naming and necessity. Cambridge: Harvard University Press.

Kroedel, T. (2012). Counterfactuals and the epistemology of modality. Philosophers Imprint, 12(12), 1-14.

Kung, P. (2010). Imagining as a guide to possibility. Philosophy and Phenomenological Research, 81(3), $620-663$.

Legg, C. (2012). The hardness of the iconic must: can Peirce's existential graphs assist modal epistemology? Philosophia Mathematica, 20(1), 1-24.

Legg, C., \& Franklin, J. (2017). Perceiving necessity. Pacific Philosophical Quarterly, 98(3), 320-343.

Leon, F. (2017). From Modal Skepticism to Modal Empiricism. In B. Fischer \& F. Leon (Eds.), Modal epistemology after rationalism (pp. 247-262). Berlin: Springer.

Lewis, D. K. (1986). On the plurality of worlds. Oxford: Blackwell.

Liao, S., \& Gendler, T. S. (2011). Pretense and Imagination. Wiley Interdisciplinary Reviews, 2(1), 79-94.

Lowe, E. J. (2008). Two notions of being: entity and essence. Royal Institute of Philosophy Supplement, $62,23-48$.

Lowe, E. J. (2012). What is the source of our knowledge of modal truths? Mind, 121(484), 919-950.

Mallozzi, A. (ms.). Non-uniform modal epistemology.

Mallozzi, A. (2018). Two notions of metaphysical modality. Synthese, pp. 1-22.

McFetridge, I. (1990). Logical necessity: some issues. In J. Haldane \& R. Scruton (Eds.), His logical necessity and other essays (pp. 135-154). London: Aristotelian Society.

Menzies, P. (1998). Possibility and conceivability: A response-dependent account of their connections. In R. Casati (Ed.), European review of philosophy (Vol. 3, pp. 255-277). Stanford: CSLI Publications.

Nichols, S., \& Stitch, S. (2003). Mindreading: An integrated account of pretence, self-awareness, and understanding other minds. Oxford: Oxford University Press.

Nolan, D. (2017). Naturalised modal epistemology. In B. Fischer \& F. Leon (Eds.), Modal epistemology after rationalism (pp. 7-27). Berlin: Springer.

Peacocke, C. (1999). Being known. Oxford: Clarendon Press.

Peacocke, C. (2019). The primacy of metaphysics. Oxford: Oxford University Press.

Roca-Royes, S. (2017). Similarity and possibility: An epistemology of de re possibility for concrete entities. In B. Fischer \& F. Leon (Eds.), Modal epistemology after rationalism (pp. 247-262). Berlin: Springer.

Roca-Royes, S. (2018). Rethinking the epistemology of modality for abstracta. In I. Fred-Rivera \& J. Leech (Eds.), Being necessary: Themes of ontology and modality from the work of Bob Hale (pp. 245-265). Oxford: Oxford University Press.

Roca-Royes, S. (Forthcoming). The integration challenge. In O. Bueno, \& S. Shalkowski (Eds.), The Routledge handbook of modality. Routledge.

Sidelle, A. (1989). Necessity, essence, and individuation: A defense of conventionalism. Ithaca, NY: Cornell University Press.

Strohminger, M. (2015). Perceptual knowledge of nonactual possibilities. Philosophical Perspectives, 29(1), $363-375$.

Strohminger, M., \& Yli-Vakkuri, J. (2017). The epistemology of modality. Analysis, 77(4), 825-838.

Sveinsdóttir, Á. (2008). Essentiality conferred. Philosophical Studies, 140(1), 135-148.

Tahko, T. E. (2017). Empirically-informed modal rationalism. In B. Fischer \& F. Leon (Eds.), Modal epistemology after rationalism (pp. 29-45). Berlin: Springer. 
Tahko, T. E. (2018). The epistemology of essence. In A. Carruth, S. C. Gibb, \& J. Heil (Eds.), Ontology, modality, mind: Themes from the metaphysics of E. J. Lowe (pp. 93-110). Oxford: Oxford University Press.

Teitel, T. (2019). Contingent existence and the reduction of modality to essence. Mind, 128, 39-68.

Thomasson, A. L. (2013). Norms and necessity. Southern Journal of Philosophy, 51(2), 143-160.

Thomasson, A. L. (Forthcoming). Norms and necessity. Oxford University Press.

Vaidya, A. (2017). Modal knowledge: Beyond rationalism and empiricism. In B. Fischer \& F. Leon (Eds.), Modal epistemology after rationalism (pp. 85-114). Berlin: Springer.

van Inwagen, P. (1998). Modal epistemology. Philosophical Studies, 92(1), 67-84.

Vetter, B. (2015). Potentiality: From dispositions to modality. Oxford: Oxford University Press.

Vetter, B. (2016). Williamsonian modal epistemology, possibility-based. Canadian Journal of Philosophy, 46, 766-795.

Williamson, T. (2007). The philosophy of philosophy. Oxford: Blackwell.

Williamson, T. (2013). How deep is the distinction between a priori and a posteriori knowledge? In A. Casullo \& J. Thurow (Eds.), The a priori in philosophy (pp. 291-313). Oxford: Oxford University Press.

Williamson, T. (2016). Modal science. Canadian Journal of Philosophy, 46, 453-492.

Yablo, S. (1993). Is conceivability a guide to possibility? Philosophy and Phenomenological Research, $53(1), 1-42$.

Publisher's Note Springer Nature remains neutral with regard to jurisdictional claims in published maps and institutional affiliations. 